\title{
HEIDEGGER: DE AGOSTINHO A ARISTÓTELES
}

\author{
Costantino Espósito ${ }^{1}$ \\ esposito@filosofia.uniba.it
}

RESUMO O artigo trata da presença de St. Agostinho no pensamento heideggeriano. Agostinho não representa apenas uma fonte importante para a formação do jovem Heidegger (junto com a fenomenologia de Husserl e a filosofia aristotélica), mas também uma tendência fundamental, algumas vezes tácita, que Heidegger procura absorver e metabolizar em seu próprio pensamento.

A interpretação das Confissões - em particular as leituras sobre memoria e temptatio no livro X e sobre o tempo no livro XI, realizadas durante o curso sobre Agostinho e o Neoplatonismo - é a oportunidade que tem Heidegger para tomar algumas decisões teóricas básicas. O homem é um "ser-aî" histórico e temporal que levanta a questão do ser, porque ele é em si mesmo esta própria questão. Enquanto para St. Agostinho o homem é o ente que pergunta diante de um Tu, no pensamento de Heidegger, a questão do homem - a pergunta que é o homem - é entregue ao "nada", porque o mistério de ser não pode mais se manifestar como uma presença.

A possibilidade de uma confissão, entendida como um diálogo dramático entre o "Eu" e a presença do ser, torna-se para Heidegger o sinal de finitude do "ser-ai" e de impossibilidade do próprio ser. O objetivo deste artigo é mostrar a atenção de Heidegger (em alguns cursos e ensaios escritos no início dos anos vinte) em "salvar" a descoberta agostiniana de inquietudo, interpretando-a a partir da noção aristotélica de physis - o ente que traz

1 Facoltà di Lettere e Filosofia dell'Università di Bari. Recebido em 28/09/2009 e aprovado em 19/12/2009.

KRITERION, Belo Horizonte, nº 121, Jun./2010, p. 21-46. 
consigo o princípio do movimento - como uma cinética autorreferencial da vida.

Palavras-Chave História da metafísica, Fenomenologia da vida religiosa, Martin Heidegger, Agostinho de Hipona, Aristóteles, "Ser-ai", Questão do ser, Memória, Tentação, Tempo, Física, Cinética da vida

ABSTRACT The paper deals with Augustine's presence in Heidegger's thought. Indeed, Augustine is not only the main source for the young Heidegger's training (together with Husserl's phenomenology and Aristotle's philosophy), but is also the fundamental inclination, sometimes hidden, that Heidegger tries to absorb and metabolize in his own thought.

The Confessions' interpretation - in particular the reading of book $X$ on memoria and temptatio and book XI on time faced during the Lectures on Augustin and Neoplatonism - is the chance Heidegger has to make some basic theoretical decisions. Human being is nothing but an historical and temporal being-there who raises the question of being because he is in himself that question. While for Augustine the question is raised before a You, in Heidegger's thought the question of human being - i.e. the question that human being is - is handed over to "nothing", because the mystery of being can never become a presence.

The possibility of a confession, as a dramatic dialogue between the I and the presence of being, becomes for Heidegger the sign of the finitude of the being-there and the impossibility of being in itself. The aim of the paper is to show Heidegger's attempt (in some lectures and articles wrote during the early Twenties) to "save" Augustine's discovery of inquietudo interpreting it on the ground of Aristotle's physis - i.e. that being which has within itself the principle of the movement - as a self-referential kinetics of life.

Keywords History of Metaphysics, Phenomenology of Religious Life, Martin Heidegger, Augustine of Hippo, Aristotle, Being-there, Question of being, Memory, Temptation, Time, Physics, Kinetics of life

1 Como acontece com poucos outros nomes - talvez somente o de Nietzsche e o de Hölderlin - aos olhos de Heidegger o nome de Agostinho não indica somente um autor, mesmo se essencial, na história do pensamento, mas coincide propriamente com a experiência de vida de quem possuía este 
nome: ou melhor, de quem o possui. É por isso que a relação de Heidegger com Agostinho merece ser contada, pois constitui um momento privilegiado na história do questionamento de Heidegger, um questionamento que, por sua vez, diz respeito ao acontecer da vida, ou seja, à história essencial do ser. Ao mesmo tempo - esta é a tese que gostaria de propor - para Heidegger o encontro com Agostinho pode se realizar somente na medida em que este encontro se traduz e ao mesmo tempo se baseia na posição aristotélica sobre o ser da vida: e isto não porque após a sugestão de Agostinho apareça ou retorne uma outra perspectiva e um outro contexto problemático, mas, ao contrário, porque somente Aristóteles pode e deve salvar, paradoxalmente, a descoberta que, depois dele, Agostinho foi o primeiro a fazer. Nesta inversão cronológica fica claro para Heidegger algo como um destino. Cabe-nos a tarefa de retomar o paradoxo e verificar a opção que está atrás desta suposta necessidade - uma opção escondida, mas, no entanto, evidente em sua orientação.

$2 \mathrm{O}$ que se revela, na leitura que Heidegger oferece de Agostinho, é uma verdadeira descoberta de significados originários do ser da vida, ou melhor, da vida como lugar em que ocorrem os mais genuínos significados do ser. Esta pesquisa ontológica da existência se evidencia através de três fios condutores, que constituirão a textura da interpretação:

a) o ser como ter, indicando a "facticidade" da vida;

b) o ser como acontecer, o que constitui o "ser histórico" da vida;

c) o ser como procurar, que caracteriza a "preocupação" da vida.

O existir - digo aqui de forma preliminar, mesmo considerando o trabalho hermenêutico realizado por Heidegger nos seus primeiros cursos de Freiburg, em que procura circundar e quase colher o fenômeno em questão ${ }^{2}$ - não pode ser objetivado em nenhuma determinação "efetiva", em nenhum dado "real". A vida, a existência "acontece" sem nunca "se realizar", pois toda realização conduziria à perda do próprio ser em um dado ôntico, e o viver significaria simplesmente ser o que se é - e somente isso. Para Heidegger, ao contrário, é a diferença ou transcendência entre o que se é e o próprio ser que conota o ente existente. Nisto reside, com efeito, o sentido de sua "historicidade" originária (ou melhor, de seu ser-histórico), que não deve ser entendida nos termos de um acontecimento, mas no sentido de uma realização originária. A vida não chega à sua atuação por algo que acontece, mas se atua simplesmente existindo

2 Remeto somente a Kisiel, Th. The Genesis of Heidegger's Being and Time. Berkeley; Los Angeles: University of California Press, 1993. cap. 2 (em part. parte 1) e a Fabris, A. L'“ermeneutica della fatticità" nei corsi freiburghesi dal 1919 al 1923. In: Volpi, F. (Org.). Guida a Heidegger. Roma; Bari: Laterza, 2005. p. 59-111. 
(ou, como diz Heidegger, o atuar-se é o mesmo "como" do existir). Neste movimento do "ser-aí" que se "possui" enquanto se atribui a si mesmo reside a sua "facticidade" radical. E na base desta facticidade, mesmo se parece paradoxal, a vida não é um dado, muito menos é dada por..., mas é o movimento do dar-se a si mesma. Nesta autodoação se verifica uma espécie de movimento endógeno da vida, que não pareceria requerer nenhum outro fator - nenhum fator "outro" - que a realize, resolvendo assim toda proveniência ontológica, toda dependência do ser, em uma finitude ab-soluta, como constituição fundamental do existir. ${ }^{3}$ Mas isto constituirá o viés especificamente "aristotélico" (no sentido específico que Heidegger dá a este termo) da descoberta de Agostinho.

Quando em 1927 Heidegger introduz - no início de Ser e tempo ${ }^{4}$ - a tarefa de uma interpretação do ser-aí em sua modalidade mais imediata e mais próxima, ou seja, a "quotidianidade média", cita diretamente o "trabalho", quer dizer, a "elaboração" existencial (mais do que teórica ou prática) que a vida faz de si mesma exatamente com as palavras de Agostinho: "Ego certe laboro hic et laboro in meipso: factus sum mihi terra difficultatis et sudoris nimii" ("eu trabalho certamente aqui e trabalho dentro de mim mesmo: tornei-me, para mim mesmo, terra de dificuldade e de intenso suor"). ${ }^{5}$ Trata-se de um contexto que torna, por assim dizer, mais transparente a importância de Agostinho em relação à pesquisa de Heidegger. Como sabemos, trata-se, no interior da analítica ontológico-existencial, de propor novamente a questão do ser, partindo da consideração de que procurar (ou perguntar), antes ainda de ser uma tematização teórica, ou uma disposição prática do ser-aí, é o seu modo mais próprio de ser como "o que procura”. E não porque este procure algo que não possua, mas porque existir quer dizer o ser em questão de si mesmo e o ser em questão do ser ele mesmo (o ser-aí, lembremos, é o ente em que está em jogo o próprio ser). ${ }^{6} \mathrm{O}$ ser-aí “é” uma relação estrutural com o próprio ser

3 Cf., por exemplo, dois dos primeiros cursos de Freiburg: Heidegger, M. Phänomenologische Interpretationen zu Aristoteles: Einführung in die phänomenologische Forschung (WS 1921/22). "Gesamtausgabe" (= GA) Bd. 61, hrsg. v. BRÖCKER, W.; BRÖCKER-OLTMANNS, K. Frankfurt am Main: Klostermann, 1985. p. 130 (trad. it. de M. De Carolis, ed. por E. Mazzarella. Interpretazioni fenomenologiche di Aristotele: Introduzione alla ricerca fenomenologica. Napoli: Guida, 1990. p. 160) e Ontologie: Hermeneutik der Faktizität (SS 1923), GA Bd. 63, hrsg. v. BRÖCKER-OLTMANNS, K. Frankfurt am Main: Klostermann, 1988. p. 15 et seq. (trad. it. de G. Auletta, org. por E. Mazzarella, Ontologia: Ermeneutica della effettività. Napoli: Guida, 1992. p. 24 et seq.).

4 HEIDEGGER, M. Sein und Zeit. Tübingen: Niemeyer, 1927, 1977 ${ }^{14}$, p. $43-44$ (nova edição italiana por F. Volpi, a partir da tradução de CHIODI, P. Essere e tempo. Milano: Longanesi, 2005. p. 62).

5 AGOSTINHO, Aurélio. Confessionum libri tredecim: confissões. Texto latim da ed. Skutella revisto por M. Pellegrino, [trad. it. e notas de C. Carena. Città Nuova: Nuova Biblioteca Agostiniana], Roma 19936 , X, 16.25.

6 HEIDEGGER. Sein und Zeit, § 4, p. 16 (trad. it. p. 24). 
nos termos de uma compreensão e interpretação do significado - no mais das vezes, implícito, mas, de forma escondida, básico - do próprio ser. Todos os seus modos de ser podem ser conduzidos a este "procurar":

[...] dirigir o olhar, compreender, apreender conceitualmente, escolher, aceder a, são comportamentos constitutivos do procurar, e por isso igualmente modos de ser de um determinado ente, daquele ente que nós mesmos, os que procuram, sempre somos.

Mas, por sua vez, e de modo também originário, este procurar é orientado de modo essencial em direção ao que é procurado e a partir dele:

A posição deste problema [o problema do ser], enquanto modo de ser de um ente, é ela mesma determinada, essencialmente, por aquilo a propósito do qual nele se procura: pelo ser. Este ente, que nós mesmos somos sempre e que, além do mais, possui a possibilidade de ser que consiste em colocar o problema, nós o designamos com o termo ser-aí. ${ }^{7}$

Se o ser deve, portanto, ser procurado, é porque nós somos entes que procuram; mas nós possuímos o modo de ser do procurar porque o procurado nos pertence de forma constitutiva. Correndo conscientemente o risco de cair em um círculo vicioso - procurar o sentido do ser pressupondo o ser do ser-aí, ou seja, o que se está procurando -, Heidegger inverte a dificuldade e individua, na referência de quem procura (o ser-aí) ao procurado (o ser) a chave para a manifestação do sentido do ser.

É exatamente neste ponto, a meu ver, que se introduz o problema agostiniano em Heidegger, segundo uma dupla consideração: como o momento de maior proximidade e, ao mesmo tempo, já como o momento da separação decisiva. É profundamente agostiniano o tema do procurar compreendido como a estrutura originária da vida, e uma concepção da pesquisa tal que não só ela visa a um reencontro, mas, mais radicalmente, move-se a partir de um reencontro. Mas aqui o direcionamento da dinâmica do procurar e do procurado é certamente heideggeriano: o perguntar próprio ao ente que procura, o procurar que pertence ao seu próprio ser pode ser compreendido somente nos termos de um procurar sem encontrar. E isto não porque não seja possível atingir o que se procura enquanto diverso de nós, mas porque nós já somos o que procuramos, na medida em que somos destinados a nós mesmos.

7 HEIDEGGER. Sein und Zeit, § 2, p. 10 (trad. it. p. 19). Sobre o "perguntar" como dinâmica de fundo de todo o percurso de Sein und Zeit, cf. ESPOSITO, C. Il periodo di Marburgo (1923-28) ed "Essere e tempo": dalla fenomenologia all'ontologia fondamentale. In: VOLPI, F. (Org.). Guida a Heidegger, p. 113-166 (em part. p. 115 et seq.) e [ESPOSITO, C.; MARINI, A.; SINI, C.; VATTIMO, G.; VITIELLO, V.; von HERRMANN, F.-W]. Dialogo su "Essere e tempo". Org. por C. Bonaldi e E.S. Storace. Milano: Albo Versorio, 2003. p. 19-24. 
Procuremos, porém, ver mais de perto estas questões, retomando brevemente o encontro de Heidegger com as Confissões de Agostinho, e, mais em particular, a sua leitura do fenômeno extremamente significativo para a interpretação do ser da vida que emerge no livro $X$, e que reside na descoberta da memória e na experiência da temptatio (tentação). $\mathrm{O}$ encontro acontece na célebre Vorlesung (curso acadêmico) proferida na Universidade de Freiburg, em Breisgau, no semestre de verão de 1921, chamada Agostinho e o neoplatonismo. ${ }^{8}$

3 Quaerere Deum (procurar a Deus): ${ }^{9}$ é este o movimento mais radical da vida em Agostinho, e é na urgência da procura diante de Deus que se revela o significado último do confiteri (ou da confissão). Heidegger percebe, com perspicácia, o caráter ontológico (e não somente psicológico, ético ou teórico) desta procura e o papel constitutivo desta "confissão" para a vida do eu, mas ao mesmo tempo as compreende de tal modo que o objeto da procura e o interlocutor da confessio são, de modo progressivo e inevitável, novamente absorvidos na atuação do próprio procurar enquanto procurar: como se o confessar devesse se realizar diante de si mesmo. A transcendência do eu para o "Tu, Domine" ("Tu, Senhor") é assim interpretada como autotranscendência do existir em si mesmo, de si mesmo e para si mesmo.

"No homem - escreve Agostinho - há algo que até mesmo o espírito que está nele não conhece" (Conf., X, 5.7). A confissão não diz respeito somente ao que um homem sabe de si, mas também àquilo que não sabe. $\mathrm{E}$ o que sei, com certeza? "Domine, amo te" ("Senhor, te amo") (Conf., X, 6.8). Em Agostinho, como é evidente, o pensamento nasce da afeição, ou seja, o conhecimento de mim é possível somente enquanto evidência de uma relação e de

8 HEIDEGGER, M. Augustinus und der Neuplatonismus, hrsg. v. C. Strube, em Phänomenologie des Religiösen Lebens, GA Bd. 60. Frankfurt am Main: Klostermann, 1995. p. 158-299 (trad. it. de G. Gurisatti, org. por F. Volpi: Agostino e il neoplatonismo, em Fenomenologia della vita religiosa. Milano: Adelphi, 2003. p. 205-379. Uso esta edição, levemente modificada). Uma apresentação sintética da interpretação heideggeriana das Confissões encontra-se em von HERRMANN, F.-W. Die "Confessionen" des Heiligen Augustinus im Denken Heideggers, em Heidegger e i medievali, v. 1 de "Quaestio: Annuario di storia della metafisica”, org. por C. Esposito e P. Porro, Brepols-Pagina, Turnhout-Bari, 2001. p. 113-146.

9 As páginas seguintes retomam algumas considerações que desenvolvi em publicações anteriores: cf. ESPOSITO, C. Quaestio mihi factus sum: Heidegger di fronte ad Agostino, em Ripensare Agostino: interiorità e intenzionalità (Atti del IV Seminario internazionale del Centro di Studi Agostiniani di Perugia), org. por L. Alici, R. Piccolomini e A. Pieretti, Institutum Patristicum "Augustinianum", Roma 1993, p. 229259; Id. Die Gnade und das Nichts. Zu Heideggers Gottesfrage. In: "Herkunft aber bleibt stets Zukunft". M. Heidegger und die Gottesfrage, hrsg. v. P.-L. Coriando, Klostermann ("Martin-Heidegger-Gesellschaft Schriftenreihe", Bd. 5), Frankfurt a.M., 1998. p. 199-223; Id., Martin Heidegger: La memoria ed il tempo, em Agostino nella filosofia del Novecento. v. 1: Esistenza e libertà, org. por L. Alici, R. Piccolomini e A. Pieretti, Città Nuova, Roma, 2000. p. 87-124; Id., L'essere, la storia, la grazia in Heidegger, in Nichilismo e redenzione, org. por R. Bruno e F. Pellecchia. Milano: Franco Angeli, 2003. p. 184-207. 
um ser affectus por algo diferente. Mas o que amo, quando amo Deus? (Quid autem amo, cum te amo?).

Quem é aquele que está sobre a minha alma? Atravessando a minha alma [per ipsam animam meam] subirei até ele; transcenderei [transibo] a força com que me aperto ao corpo e que enche de potência vital o meu organismo. [...] Transcenderei, pois, também a minha potência natural [vim naturae meae], ascendendo por graus até aquele que me fez e chegarei nos campos e nos vastos palácios da memória [et venio in campos et lata praetoria memoriae $\left[\right.$ [...]. ${ }^{10}$

Entrando com Agostinho na vastidão secreta e surpreendente da memória, onde ele vai à procura do vulto e da presença do objeto de seu amor, sobre o qual nenhuma outra criatura além dele mesmo pudera dar uma resposta satisfatória, Heidegger nota o significado inaugural do gesto de Agostinho, começando, porém, a direcioná-lo segundo uma outra trajetória:

Em sua ascensão progressiva e superadora, Agostinho chega no vasto campo da memória. [...] Os fenômenos concretos que Agostinho apresenta, puramente em termos de conteúdo, e principalmente como ele explica os fenômenos, em quais contextos e quais determinações fundamentais - por exemplo, a beata vita -, supera o quadro e a estrutura da concepção corrente. Na memória estão presentes as inumeráveis imagens das coisas e ao mesmo tempo tudo o que nós - analisando-as a fundo, ampliando-as, associando-as, elaborando-as - pensamos delas: "penetrale amplum et infinitum" ("câmara ampla e infinita"). Tudo isso pertence a mim mesmo, porém eu mesmo não o apreendo. Para ter a si mesmo, o espírito é demasiado estreito. Mas onde estará então aquilo que o espírito não apreende em si mesmo? Stupor apprehendit me ... (o estupor tomam conta de mim). ${ }^{11}$

A memória é uma grande potência para Agostinho, uma potência grande demais (magna vis est memoriae, magna nimis), um santuário vasto, infinito, em cujo fundo ninguém nunca chegou (quis ad fundum eius pervenit?), de modo a ser obrigado a reconhecer - tomado pelo estupor - que eu mesmo não consigo apreender tudo o que sou (nec ego ipse capio totum, quod sum, Conf. $\mathrm{X}, 8.15$ ). Na memória estão presentes (praesto sunt) as imagens de todas as coisas, os objetos sensíveis e os objetos não sensíveis ou inteligíveis (as proposições e as regras matemáticas, assim como os conteúdos recebidos das artes liberais), e todas as affectiones animi (afeições da alma); mas "ibi [na memória] mihi et ipse occurro meque recolo, quid, quando et ubi egerim quoque modo, cum agerem, affectus fuerim" (Conf. X, 8.14): aí encontro também 
eu mesmo e me lembro de mim nos atos que realizei, no tempo e no lugar em que os realizei, nas afeições que senti realizando-os.

O ser da vida é assim identificado com a compreensão de uma incompreensibilidade em relação a si mesmo, com o enigma do ter- $a$-si, como nota Heidegger de forma sutil, comentando o que Agostinho escreve a respeito da experiência ontologicamente inexplicável que todos nós fazemos, quando presentificamos os afetos conservados na memória, mas em uma situação afetivamente mudada em relação ao passado (como quando, por exemplo, tornase presente, com alegria, uma tristeza passada). O ser si mesmo, ou melhor, o "ser" de si é aqui identificado, e vivido, como a modalidade específica de ter a si mesmo, ou melhor, do "ter" que é uma forma de autopossessão - na memória e como memória - do que não se pode possuir. "O ter, portanto, é visto por Agostinho como algo peculiar, próprio [eigenes]!”. Este é, segundo Heidegger, um dos Vollzugsrätseln, os "enigmas da atuação", ${ }^{12}$ e que nos lembra o plexo cooriginário que, em outros cursos universitários de Freiburg, é instituído entre o "ser si mesmo" (Selbstsein) ou o "mundo do si" (Selbstwelt), e a situação factual fundamental que é o "ter-a-si-mesmo" (Sich-selbst-Haben) ou o "levar o si mesmo ao possuir" (Sich-selbst-zum-Haben-Bringen), e entre esta última situação e o "ter (a) história" (Geschichte Haben), que consiste na autoatuação da vida como existência. A história é o meu ser - ou seja, o modo em que "tenho" a mim mesmo - na medida em que "ter" algo, um "conteúdo" (Gehaltsinn), se manifesta na modalidade da pura "relação" consigo mesmo (Bezugssinn), e nesta autorreferência chega a se atuar (Vollzugssinn). ${ }^{13}$ Se se considera este "ter a si" como "ter a morte", ${ }^{14}$ compreende-se o significado radical que Heidegger atribui a esta atuação da posse de si e da recepção de si em sentido rigorosamente antiobjetivista, como uma espécie de autorreferencialidade factual.

12 HEIDEGGER. Augustinus und der Neuplatonismus, GA Bd. 60, respectivamente p. 187 e 182 (trad. it., p. 243 e 238).

13 Cf. HEIDEGGER, M. Grundprobleme der Phänomenologie (WS 1919/20), GA Bd. 58, hrsg. v. H.-H. Gander. Frankfurt am Main: Klostermann, 1993. p. 59 et seq., 253; Phänomenologie der Anschauung und des Ausdrucks: Theorie der philosophischen Begriffsbildung (SS 1920), GA Bd. 59, hrsg. v. C. Strube. Frankfurt am Main: Klostermann, 1993. p. 52-54; Phänomenologische Interpretationen zu Aristoteles..., GA Bd. 61, p. 171 (trad. it., p. 200); Einleitung in die Phänomenologie der Religion (WS 1920/21), hrsg. v. M. Jung und T. Regehly, em Phänomenologie des Religiösen Lebens, GA Bd. 60, Frankfurt am Main: Klostermann, 1995. p. 3-156, aqui p. 31 et seq., 63.

14 HEIDEGGER, M. [Natorp Bericht (1922) =] Phänomenologische Interpretationen zu Aristoteles (Anzeige der hermeneutischen Situation), hrsg. v. LESSING, H.-U. “Dilthey Jahrbuch”, 6, p. 237-269, 1989, aqui p. 244 (trad. it. de G. P. Cammarota e V. Vitiello: Interpretazioni fenomenologiche di Aristotele: Prospetto della situazione ermeneutica, "Filosofia e Teologia", 4, p. 496-532, [1990], aqui p. 504). Ver a nova edição crítica do texto de G. Neumann. Stuttgart: Reclam, 2002. 
Em Agostinho, Heidegger encontra o caminho para chegar à facticidade como autoatuação da existência, e a encontra no que chama de "aporia em relação ao esquecimento" (die Aporie bezüglich der oblivio). O esquecimento (o não estar presente na memória, ou, melhor ainda, a privatio memoriae: Conf. $\mathrm{X}, 16.24)$ é ele mesmo presente na memória, assim como estão presentes os conteúdos lembrados, de modo que Agostinho pode afirmar que é a memória que conserva o esquecimento: "memoria retinetur oblivio". Trata-se de um fenômeno que terá um papel determinante no pensamento de Heidegger: "O esquecimento deve pois estar presente em si mesmo. Se eu me torno novamente presente o esquecimento (esquecimento/oblivio: o ter esquecido e ao mesmo tempo o que é esquecido), este é praesto: 'memoria qua meminerim, oblivio quam meminerim' ('a memória, com que lembro, o esquecimento, de que lembro')". ${ }^{15}$

Mas esta presença do esquecimento não deve ser vista somente de modo "negativo", como o desfazer-se da lembrança, dado que possui um seu modo peculiar de ser, completamente diferente da dinâmica psicológica, mais conotável como um fenômeno originário: não algo (uma imagem, uma noção, um sentimento) que se perde - ou seja, que não é mais lembrado -, mas uma "coisa" que se "realiza" em si mesma.

Oblivio, esquecimento, possui caráter de referência [...]: não ter presente - algo que tinha sido presente e que deveria ser agora - enquanto não ter presentemente disponível, ou seja, enquanto ausência de memória. Este ser-ausente que se encontra no sentido da referência é apreendido - por isso deve ser visto como tal - como não-ser-aí [Nichtdasein], no sentido mencionado de não-ser-praesto, e precisamente com um caráter próprio de realização. Disso deriva a antinomia: se há memória presentificação - não pode haver oblivio, e vice-versa. Se há oblivio, eu não sou capaz de presentificar, de modo que o próprio esquecimento - em termos de conteúdo - não há. ${ }^{16}$

O que significa "ter" o que não se possui, ou melhor, em que modo o seraí possui a si como não existente? Para não esquecer, nós temos presente o que com a sua própria presença nos faria esquecer: "Adest ergo, ne obliviscamur, quae cum adest, obliviscimur" ("por isso é presente, para não esquecer, o que, com sua presença, nos faz esquecer") (Conf. X, 16.24). Assim, como sugere Agostinho como último passo, seria possível deduzir que não existe o esquecimento em si mesmo (pois, como se disse, se existisse não poderia sequer ser lembrado como tal), mas a sua imagem. Só que esta suposta solução na 
realidade duplica o problema do nexo memória-esquecimento, pondo o problema da relação entre a "impressão" ou traço - o que se encontra "já imprimido" (iam notatum) na memória - e o seu cancelamento. Com efeito,

mesmo admitindo que esteja presente somente a imagem da presentificação, esta deve, porém, existir por si mesma, de modo que eu possa adquirir a imagem. Mas como pode acontecer isto, visto que o esquecimento cancela, segundo o seu sentido, o que, enquanto notatum, estaria disponível? "Et tamen [...] ipsam oblivionem [o ter esquecido] meminisse me certus sum, qua id quod meminerimus [o que queremos tornar novamente presente] obruitur" ("e todavia ... estou certo de lembrar o próprio esquecimento, o que destrói o que queremos lembrar") [Conf. X, 16.25]. ${ }^{17}$

A aporia do esquecimento na memória - ou seja, o fato que eu estou certo de lembrar também o mesmo esquecimento, o que destrói a memória - é o que obriga a colocar novamente a questão sobre como se deva procurar, ou ainda, sobre "o que significa procurar" (was heißt Suchen?). Aqui, talvez, valha a pena indicar que esta pergunta é a tradução fenomenológica - se quisermos, neutra, mas ambígua - proposta por Heidegger da questão explícita posta adiante pelo próprio Agostinho, diante do interlocutor divino: "Quomodo ergo te quaero, Domine?" (“em que modo te procuro, Senhor?”) (Conf. X, 20.29). O que quer dizer, para ambos: o que é o ser-homem? No que consiste a vida como procura? E, vice-versa, em que modo o procurar "é" existir? Somente que nos dois casos, como veremos, muda o sentido último do perguntar, pois em Heidegger o te, Domine, parece se dissolver completamente no "como" (quomodo) do procurar (quaero).

O "que significa procurar" deve ser compreendido - na sua plena dinâmica fenomenológica, ou seja, em vista do seu preenchimento intencional - nos termos de "o que significa encontrar": mas também aqui, no nexo procurar/encontrar, a proximidade entre Heidegger e Agostinho se inverte em separação. Vejamos. Procurar significa transcender: transcender não somente a potência vital e a faculdade sensorial, mas também a memória, para atingir aquilo, ou melhor, aquele que se procura. Todavia, nota Agostinho, se te encontro fora da minha memória, permaneço imêmore, esquecido, de ti (si praeter memoriam meam te invenio, immemor tui sum); e como poderia ter te encontrado se não tivesse memória de ti? (et quomodo iam inveniam te, si memor non sum tui?. Conf. X, 17.26). Assim, segundo Heidegger, o que eu procuro para poder encontrar, ou seja, o próprio procurado, já devo "tê-lo", segundo o exemplo evangélico, lembrado por Agostinho, da mulher que procura a moeda perdida, 
e pode reencontrá-la, enquanto já houvera notícia na memória. O sentido de realização do "ser" como "ter" encontra aqui o seu ponto de manifestação mais aguda: "“ser" = ter. - Ter em sentido próprio = não ter perdido; ter em referência ao poder perder - na angústia - possibilidade - intencionalidade! ser-aí - objetivo»; ou ainda, mais precisamente:

[...] ao procurar este algo como Deus, eu mesmo apareço em um papel completamente diferente. Não sou somente aquele a partir do qual o procurar se origina, dirigindose em uma direção qualquer, ou no qual o procurar acontece, já que a atuação da própria procura é algo do próprio procurar. ${ }^{18}$

Portanto, o que eu procuro, quando procuro Deus? "Cum enim te, Deum meum, quaero, vitam beatam quaero. Quaeram te, ut vivat anima mea" (Conf. $X, 20.29)$. Procurar Deus significa procurar a vida, e procurar a vida tem o significado de uma Bekümmerung um Leben, ${ }^{19}$ da "preocupação da vida", ou melhor, da "inquietude do viver", a inquietude que é o próprio viver como "cuidado". De modo que o problema vai ser: se a pesquisa de Deus implica o modo em que a vida já o teve - enquanto procurado - então como se "tem" a vida beata, qual é o modo em que o eu já possui esta vida em si? Se de algum modo não o tivesse, não poderia sequer desejá-la: "a noção ou cognição [notitia] que possuímos da felicidade nos faz amá-la, e, porém, procuramos ainda possuí-la para sermos felizes" (Conf. X, 21.30). Nós não gostaríamos de algo "com uma vontade tão decidida [certa voluntate], se não o conhecêssemos com certeza [certa notitia]" (Conf. X, 21.31).

E a notitia de que aqui se trata não é somente sensível, mas tampouco somente intelectual, mas se relaciona, de certo modo (fortasse ita), com a experiência da alegria ou gozo (gaudium). Da alegria "sou experiente na minha alma, quando estou alegre, e é presente sua notícia na minha memória" "expertus sum in animo meo, quando laetatus sum, et adhaesit eius notitia memoriae meae" (Conf. X, 21.30): é pela experiência de uma alegria, de um contentamento, que a cognição da alegria penetra e por assim dizer se imprime na minha memória. É aqui que Heidegger nota uma significativa mudança na dinâmica do experimentar, pois neste caso a experiência não seria mais identificada com um conteúdo determinado (o que se experimenta cada vez), mas com o "si mesmo" que se torna expertus, e mais precisamente, com o si mesmo que se alegra. A mudança aconteceria na própria experiência da

18 HEIDEGGER. Augustinus und der Neuplatonismus, GA Bd. 60, respectivamente p. 190-191 e 192 (trad. it., p. 248-250).

19 Cf. HEIDEGGER. Augustinus und der Neuplatonismus, GA Bd. 60, p. 193 (trad. it., p. 251). 
alegria, não mais entendida como um "conteúdo", mas como a modalidade, o "como" em que se atua a vida do eu. A pergunta sobre $o$ que é a alegria se afina e se realiza na pergunta sobre como esta seja possuída pelo si-mesmo. É exatamente nesta "situação de atuação" (Vollzugssituation) que se manifesta a "existência autêntica" (eigentliche Existenz), como um "referir-se radical a si mesmo, autêntica facticidade" (radikale Verweisung auf das Selbst, eigentliche Faktizität). ${ }^{20}$

Por mais paradoxal que possa aparecer, é a alegria agostiniana que indica formalmente a mais radical facticidade heideggeriana. E não é um caso que oito anos após o curso de Freiburg que aqui analisamos, mais precisamente, na conferência acadêmica sobre $O$ que é metafísica?, Heidegger volte a falar da "alegria" como um dos estados de ânimo que, bem antes de toda tematização teórica, nos levam a entender em sentido originário a existência como relação com o ser. Mas, como sabemos, no lugar da alegria ele preferirá assumir o estado de ânimo da angústia como o fenômeno mais indicativo da nossa única relação metafísica possível com o ente em totalidade, que não caia nas determinações ônticas das ciências positivas, e note assim como este ente se desfaça no "nada". ${ }^{21}$

Voltemos, porém, à leitura de Agostinho. Ter a vida beata (como atuação do si) é para todos - sem nenhuma exceção - pelo menos o não querer ser enganado, e, mais radicalmente, a alegria ou o prazer que traz a verdade: "Beata quippe vita est gaudium de veritate. Hoc est enim gaudium de te, qui veritas es" ("a vida beata é a alegria/gozo da verdade. Ou seja, a alegria/gozo de ti, que és a verdade" (Conf. X, 23.33). Heidegger nota que aqui a verdade (e a luz com que ela ilumina o eu) não deve ser entendida em sentido "metafísico" (grego), mas "existencial": pois, mais do que indicar um caráter coisal, a verdade constitui uma tendência ou uma direção da vida, assim como Agostinho atestaria ao descrever a "direção de queda" ou de "decadência" - quase como uma força de gravidez existencial, como vai ser traçada por Heidegger no curso do semestre seguinte, sobre Aristóteles ${ }^{22}$ - que consiste em odiar a verdade (Deus) em nome do que se crê, ilusoriamente, que seja a verdade: "Itaque propter eam rem oderunt veritatem, quam pro veritate amant. Amant eam lucentem, oderunt eam redarguentem" ("Assim por causa disso odeiam

20 HEIDEGGER. Augustinus und der Neuplatonismus, GA Bd. 60, p. 195-196 (trad. it., p. 253-254).

21 HEIDEGGER, M. Was ist Metaphysik?, em Wegmarken, GA Bd. 9, hrsg. v. F.-W. von Herrmann, Klostermann, Frankfurt am Main 1976, p. 110 (trad. it. de F. Volpi, Che cosè metafisica?, in Segnavia, Adelphi, Milano 1987, p. 66).

22 Cf. HEIDEGGER. Phänomenologische Interpretationen zu Aristoteles..., GA Bd. 61, p. 131 et seq. (trad. it., p. 161 et seq.). Ver também Natorp-Bericht, p. 238 (trad. it., p. 497-498). 
a verdade, pelo amor da verdade. Amam-na quando brilha, a odeiam quando redargüi”") (Conf. X, 23.34). E Heidegger comenta: a verdade é odiada quando não se colocam em questão as coisas, mas a própria facticidade da vida; todavia, também nesta posição enganadora, o que é amado é sempre a verdade. ${ }^{23}$

Onde o eu encontrou uma verdade, aí encontrou Deus: mas isto quer dizer que não é possível encontrar Deus extra memoriam (Conf. X, 24.35), ainda que Deus não seja nada de psíquico, mas o senhor da memória - "Dominus Deus animi" - o qual, em relação à mutabilidade dos estados e dos atos da alma, ou da mente, permanece "inconmutabilis" (Conf. X, 25.36). O habitar de Deus na memória não deve ser entendido, mais uma vez, em sentido objetivo e de conteúdo, mas no sentido da autoatuação do si: "onde pois te encontrei, para te conhecer, se não em ti mesmo, sobre mim [nisi in te supra me]?" (Conf. X, 26.37).

Assim, nota Heidegger, "a pergunta 'onde encontro Deus?' é invertida na discussão das condições da experiência de Deus, e isto conduz ao problema 'quem sou eu mesmo?'”. De modo que, quando Agostinho exclama com paixão: "Sero te amavi, pulchritudo tam antiqua et tam nova" (Conf. X, 27.38), a tradução de Heidegger soa: "tarde cheguei ao nível da vida factual em que me coloquei em condição [in Stand gesetzt habe] de te amar". ${ }^{24}$

A tensão dramática entre o eu e Deus tende a se resolver aqui na irredutibilidade do "como" em relação ao "o que". Neste sentido, a historicidade não pode ser entendida senão como autorreferência, e a inquietude de que fala Agostinho deverá necessariamente ser retraduzida nos termos de uma "motilidade" que encontra o seu paradigma ontológico no conceito aristotélico de physis: o ente que tem em si mesmo o princípio do movimento. A "metafísica" de Agostinho, no fundo, não seria nada mais para Heidegger do que a "física" de Aristóteles. Mas para entender esta passagem, devemos ainda dar um outro passo dentro da leitura heideggeriana de Agostinho.

4 É na experiência da temptatio (significativamente descrita, sempre dentro do livro dez das Confissões, em conexão próxima não somente de redação, mas também temática com a questão da procura de Deus na memória) que a relação entre o eu que procura e o Tu amado e reconhecido se intensifica como a vida. A descoberta de Agostinho torna-se um verdadeiro convite para a interpretação de Heidegger. Temptatio - lembremos - significa ao mesmo

23 Cf. HEIDEGGER. Augustinus und der Neuplatonismus, GA Bd. 60, p. 201 (trad. it., p. 260).

24 Esta e a próxima citação: HEIDEGGER. Augustinus und der Neuplatonismus, GA Bd. 60, p. 204 (trad. it., p. 263-264). 
tempo tentação e prova: "A vida humana na terra não seria uma prova? [ quid non temptatio est vita humana super terram?]. Quem desejaria incômodo e dificuldades? Tu nos ordene suportar o seu peso, não amá-las" (Conf. X, 28.39). É aqui que, para Heidegger, se mostra o "caráter fundamental da vida factual", ou seja, o cuidar, o cuidar de si, entendido como uma inquietude ou uma preocupação, ou ainda, um estar-preocupado estrutural (Bekümmertsein) em relação ao si mesmo. ${ }^{25}$ Neste "cuidar" o eu se manifesta em toda a sua gravidade originária: "quoniam tui plenus non sum, oneri mihi sum" (Conf. X, 28.39), próprio para não ser cheio de ti, Senhor, diz Agostinho (mas é uma motivação sobre a qual Heidegger cala), eu sou um peso para mim mesmo - e é este "pesar" puro e nu que emerge na leitura de Heidegger, quase como se prescindisse do juízo que Agostinho oferece em relação à origem deste fenômeno. $\mathrm{O}$ caráter fundamental da vida factual não deve ser entendido como uma situação anterior que se torna objeto de uma preocupação existencial, e nesta seja tematizada e considerada; ao contrário, é somente no "cuidar" que o peso próprio do existir se manifesta, ou melhor, em definitiva, coincide com este, e constitui a sua dinâmica intrínseca, a verdadeira força de gravidade da vida existente.

A tendência primária da vida, com efeito, é o que Agostinho chama de dispersão no múltiplo (defluxus in multa), e que Heidegger lê como uma dispersão na objetividade dos conteúdos determinados do viver; mas, junto a uma tal dispersão, a vida é marcada por uma específica retomada que - mediante a "continência" - conduz ao recolhimento da unidade do eu: o que somente permite "suportar" (tolerare) a prova que é a vida em si mesma: "É mediante a continência que somos recolhidos e reconduzidos à unidade da qual nos afastamos, perdendo-nos no múltiplo" (Conf. X, 29.40). E aqui Heidegger acentua, devidamente, que a continentia não pode ser entendida e traduzida em sentido negativo, como "abstinência" (Enthaltsamkeit), mas no seu sentido positivo (e literal) como o "manter-se junto" (Zusammenhalten) do eu, que é um "arrancar-se" (zurückreißen) originário da dispersão.

Neste movimento se evidencia, para Heidegger, a historicidade intrínseca da existência factual, no sentido preciso da "dinâmica" e da "conflitualidade" (Dynamik und Zwiespältigkeit) que pertencem à - ou melhor, que constituem a vida como cuidado:26 "nas circunstâncias adversas lamento o bem-estar, no

25 Cf. HEIDEGGER. Augustinus und der Neuplatonismus, GA Bd. 60, p. 205-206 (trad. it., p. 264-265).

26 Cf. HEIDEGGER. Augustinus und der Neuplatonismus, GA Bd. 60, p. 207, nota 14 (trad. it., p. 267, nota 4). No que diz respeito à dimensão da "historicidade" da vida, que não posso analisar devidamente, remeto a ESPOSITO, C. Storia e fenomenologia del possibile. 2d. ed. rev. e ampl. Bari: Levante, 2003. cap. 1 e 2 , parte 2. 
tempo do bem-estar, temo as adversidades" (Conf. X, 28.39). E Heidegger comenta: "O si-mesmo é acolhido dentro de um experenciar histórico - ainda que frequentemente o seja somente de "forma fraca". Esta preocupação de si não é algo que aconteça a mim na experiência, mas é esta mesma a atuação da experiência de mim (do eu mesmo). Com a consequência - mais heideggeriana do que agostiniana - de que "a atuação da experiência é, por si mesma, sempre na insegurança", ${ }^{27}$

Enfrentando a temptatio como experiência fundamental do si (e da atuação do si) que procura Deus, Heidegger encontra as maiores dificuldades do texto de Agostinho, mesmo excluindo, com decisão - e oportunamente - que se trate de dificuldades que podem ser conduzidas a questões de tipo moral ou psicológico, e insistindo no fato de que estas dificuldades são como o ponto em que a sua própria interpretação de Agostinho - interpretação não teológica, mas fenomenológica - deve se afirmar e se deter. ${ }^{28} \mathrm{Na}$ realidade, a opção desta "parada" metodológica por parte de Heidegger implica - além, e mais do que o respeito pelo confiteri próprio de Agostinho, que está sempre diante de Deus e a partir da graça de tê-lo encontrado - uma decisão a respeito da possibilidade (ou, respectivamente, da impossibilidade) de atuação da vida como prova. Não é casual, pois, que Heidegger, em uma passagem de seu curso, identifique precisamente o confiteri com o modo em que a vida interpreta si mesma na experiência das tentações, arriscando, porém, deste modo, resolvê-lo em uma hermenêutica completamente imanente à vida (não aos conteúdos da vida, mas à sua dinâmica interna), sem considerar o outro, o "tu" diante do qual se realiza a confissão: um "tu" certamente não negado por Heidegger em sua interpretação, mas de qualquer forma considerado, e tratado de fato como sem influência em relação ao significado e à experiência da própria prova.

Nas três formas descritas por Agostinho no livro X das Confissões, ou seja, a "concupiscentia carnis" (a concupiscência da carne), a "concupiscentia oculorum" (a concupiscência dos olhos) e a "ambitio saeculi" (ambição do mundo), a temptatio se revela, para Heidegger, como uma condição absolutamente insuperável, ou seja, insuperável próprio porque absoluta, ab-soluta de toda relação que não seja do si consigo mesmo. A vida - insiste Heidegger - é "peso" (moles) para si mesma, é uma experiência de moléstia que, considerada enquanto tal, subtrai-se a toda redenção. A "experiência vivida" (Erlebnis) realiza-se neste "peso" ou "gravidade" (Beschwernis) da vida: 
Moléstia: peso para a vida, algo que traz a vida para baixo; e o elemento autêntico do peso está no fato que a moléstia pode trazer para baixo, onde este "poder" é constituído por aquilo em que, cada vez, se atua a experiência. ${ }^{29}$

Consideremos, por exemplo, a leitura que Heidegger propõe de uma forma particular de concupiscência da carne, a que diz respeito ao aparecer, no sono, de imagens ilusórias do prazer sensual, que - sempre no sono - poderiam mesmo levar a admitir atos que uma "consciência casta" nunca consentiria acordada. "Talvez que nestes momentos não sou mais eu [numquid tunc ego non sum], Senhor meu Deus?” (Conf. X, 30.41), pergunta Agostinho: aqui me encontro diante de uma diferença tal entre sonhar e estar acordado que sou obrigado a me perguntar se seja sempre o mesmo "eu" em ambos os casos, e tenho que concluir - mais com Heidegger do que com Agostinho ${ }^{30}$ - que o conteúdo do meu "eu" não reside na consciência (im Gewissen), mas na passagem (im Übergang) do involuntário ao voluntário, ou seja, da sedução durante o sono à decisão durante o estar acordado. É nesta passagem que se manifesta uma experiência da facticidade que é a mais radical de todas as situações ônticas e efetivas em que o eu, a vida existe: nesta experiência, eu caio em mim mesmo, re-caio sempre no mundo do mim mesmo (Selbstwelt); eu "sou" e ao mesmo tempo "não sou" eu mesmo, o meu ser cai - e com isso se funda - em um mais originário não-ser.

Não é por acaso que Heidegger inclua esta série de fenômenos de que fala Agostinho como o "problema do "eu sou", e que conote, por sua vez, o ser-eu como uma experiência de "discrepância" (Zwiespältigkeit) entre ser e não-ser. Como prova ainda a leitura de um outro caso indicado nas Confissões, ou seja, o das seduções do olfato (illecebra odorum), em relação às quais Agostinho escreve que eu posso sempre errar na consciência das minhas faculdades, pelo motivo que estas estão cobertas por trevas deploráveis, e, portanto, nunca são confiáveis: e isto é o sinal do fato que "o que é dentro do espírito permanece a maior parte das vezes escondido [occultum], a não ser que não o revele a experiência [nisi experientia manifestetur]" (Conf. X, 32.48). Mas o que a experiência atesta é, pois, uma insegurança permanente, segundo a qual se diz que toda a vida é uma prova (tota temptatio), tanto que, "como podemos nos tornar melhores, assim também podemos nos tornar piores”. Assim Heidegger pode concluir:

29 HEIDEGGER. Augustinus und der Neuplatonismus, GA Bd. 60, p. 242 (trad. it., p. 308). A passagem está em um parágrafo significativamente chamado "Moléstia - a faticidade da vida".

30 Para as análises seguintes, cf. HEIDEGGER. Augustinus und der Neuplatonismus, GA Bd. 60, p. 212-214 (trad. it., p. 273-275). 
É, pois, nesta direção da experiência que deve ser originariamente procurado o simesmo. Nesta direção, e somente nesta, encontra-se a temptatio. Ou seja, na medida em que esta existe, a vida, ista vita, deve ser experienciada assim - onde o si é assumido na plena facticidade do experenciar [enquanto que é experenciada uma tentação, obtenho esta situação]. ${ }^{31}$

"O que é a vida" significa "o que é a experiência do si-mesmo", como mostrou o fenômeno da memória; mas "o que é a experiência" significa "o que é a tentação". E a tentação aos olhos de Heidegger não significa somente que o si-mesmo se perde nas diferentes possibilidades ônticas que cada vez o seduzem, mas mais a fundo, que a vida ou a existência se diferencia sempre enquanto tal de todos os conteúdos ônticos para se realizar como a "prova" do nada que ela mesma sempre pode ser. A dispersão no múltiplo não é a causa da facticidade do existir, porque, ao contrário, ela se funda sobre esta; e, por sua vez, a experiência da continentia não consistirá em uma tomada de distância do ser-factual do si-mesmo, mas, ao contrário, na sua assunção nua. ${ }^{32}$

É o que se afirmaria na segunda forma de tentação, segundo Agostinho, ou seja, a concupiscentia oculorum, definida "uma cobiça vã e curiosa, que se disfarça sob o nome de conhecimento e ciência" (Conf. X, 35.54). Heidegger acentua, a este propósito, que esta concupiscência dos olhos, ou seja, este "simples querer-ver" deve ser entendido como um olhar-se em volta no próprio mundo-ambiente, onde o ver significa "fazer passar um objeto como objeto", 33 diríamos, como algo presente à mão (vorhanden), constituído e fixado na mesma visão em que foi conhecido. Agostinho descreve o primado do ver através da simples constatação que a vista, mesmo se pertence propriamente aos olhos, é utilizada - pelo menos como expressão linguística para todos os outros sentidos: "Nós não só dizemos 'olha como brilha', ou seja, para as sensações que somente os olhos podem ter, mas dizemos também "olha que som, olha que odor, olha que sabor, olha como é áspero"' (Conf. X, 35.54); e Heidegger retoma esta descrição e a radicaliza, como a tendência objetivante que acompanha e determina todas as experiências factuais - como será retomado em Ser e tempo, na análise da "queda" do ser-aí, considerado em sua "quotidianidade", em que se torna decisivo, junto aos fenômenos da "tagarelice" e do "equívoco", também o da "curiosidade". Esta "não se

31 HEIDEGGER. Augustinus und der Neuplatonismus, GA Bd. 60, p. 217 (trad. it., p. 279). A frase entre colchetes é colocada em uma nota à margem do texto.

$32 \mathrm{Na}$ linguagem que Heidegger utilizará em Ser e tempo, poderíamos dizer que as possibilidades de "deperecimento" (Verfallen) do ser-aí se fundam originalmente no seu "ser lançado" (Geworfenheit): HEIDEGGER. Sein und Zeit, § 38: "Das Verfallen und die Geworfenheit”, p. 175 et seq. (trad. it., p. 214 et seq.).

33 HEIDEGGER. Augustinus und der Neuplatonismus, p. 224-225 (trad. it., p. 287-288). 
preocupa em ver para compreender o que vê, ou seja, não se preocupa em 'ser para' isto, mas somente em ver'. ${ }^{34}$ E também aqui Heidegger se refere ao livro X das Confissões, para tomar da descrição que Agostinho faz da concupiscência dos olhos o fenômeno paradoxal de um ver em que não somente se compreende verdadeiramente o que se vê dentro do próprio mundo-ambiente (próprio porque se quer somente "vê-lo"), mas nos livramos do próprio simesmo como ser-no-mundo, ou seja, como ser-junto ao ente que se encontra no mundo, e que é (pré)compreendido como utilizável.

A marca desta tendência interpretativa fica evidente quando Heidegger comenta a terceira forma de tentação, ou seja, a ambitio saeculi, o desejo de louvor e honras mundanos. Agostinho a descreve (Conf. X, 39.64) quando fala dos que se comprazem consigo mesmos (qui placent sibi de se), e com isto desagradam muito a ti, Senhor (multum tibi displicent), pois consideram 1) o que não é bem como se o fosse (de non bonis quasi bonis); 2) os bens de Deus como se fossem bens próprios (de bonis tuis quasi suis); 3) os bens recebidos de Deus como se fossem obtidos por próprios méritos (sicut de tuis, sed tamquam ex meritis suis); 4) os bens recebidos de Deus por graça como bens que não devem ser desfrutados junto aos demais, mas reservados para si (sicut ex tua gratia, non tamen socialiter gaudentes, sed aliis invidentes eam). E Heidegger re-traduz este fenômeno extremo de temptatio que é a ambição mundana como uma modalidade genuína de realização/atuação da experiência (Erfahrungsvollzug) do ser-aí. O bonum de que se fala aqui não deve ser entendido como "dote" (Ausstattung) do si-mesmo, algo que se possui e que se tem à disposição, como se se tratasse de um dos bens mundanos objetivamente presentes, mas como a própria existência, "este único que eu mesmo sou": não um objeto ao qual pertençam propriedades universais, mas "o como do "sou" (das Wie des "bin"). ${ }^{35}$

$\mathrm{Na}$ sedução mundana aparece diante do si-mesmo o "mundo próprio do si" (eigene Selbstwelt). O que para Agostinho constituía uma incompreensão do próprio ser - onde o reconhecimento da doação deixa o lugar para o comprazer-se consigo -, em Heidegger torna-se, paradoxalmente, o momento em que é possível (em sentido puramente fenomenológico, não em sentido de valor ou moral) a mais radical autocompreensão do "eu sou", na sua nua atribuição a si mesmo. ${ }^{36}$ A ambitio saeculi, a ambição do mundo, deste modo,

34 HEIDEGGER. Sein und Zeit, § 36, p. 172 (trad. it. modificada, p. 211).

35 HEIDEGGER. Augustinus und der Neuplatonismus, p. 238 (trad. it., p. 305).

36 Sobre a descoberta da Selbstwelt por parte do cristianismo primitivo (Urchristentum), em que Agostinho após Paulo e seguido por Bernardo de Clairvaux, Boaventura, Eckhart e Tauler, até Lutero e Kierkegaard é considerado como uma das "erupções" poderosas que revolucionaram o paradigma da "ciência antiga", 
não é mais vista como falta de atuação, mas como a manifestação plena, a atuação do si-mesmo. É principalmente comentando a segunda possibilidade desta tentação - ou seja, considerar os bens recebidos de Deus como bens próprios, como pertencendo sempre a si mesmo e a si mesmo devidos - que aparece, quase à contraluz, o perfil heideggeriano do ser-aí:

"Verum etiam de bonis tuis quasi suis" [...]: também se se conhece de forma genuína
o caráter do bem, e se ao si mesmo pertence um bem genuíno ("ser bom": existir
autêntico!) - o que, no entanto, enquanto tal, pode ser somente de Deus - este fato é
assumido diante de si mesmo, como adquirido graças a si mesmo, dado pelo si para
si mesmo (ser aí - existência), levado por si mesmo a este estado e neste estado da
existência. ${ }^{37}$

A extrema "queda" (Sturz) do ser-aí em si mesmo, a que é entendida por Agostinho como uma falsificação, se não como uma perda de si, torna-se aqui a realização mesma da facticidade, em que a moléstia (o peso da prova, a tendência irreprimível da "gravidade"), torna-se a própria possibilidade da vida, a possibilidade que é a vida: "esta possibilidade 'cresce' quanto mais a vida vive" e "quanto mais a vida atinge a si mesma", 38 tendo-se na atuação.

$\mathrm{O}$ fato de que, neste contexto interpretativo, a descrição que Agostinho faz da temptatio seja assumida e enfatizada independentemente do juízo do próprio Agostinho - o qual considera a tentação e a prova como interrupção e desconhecimento da relação que está na origem do bem, e que coincide com o bem do si, e, portanto, como "pecado" - não é, porém, casual, mas responde a uma opção metodológica precisa:

a nossa possibilidade de interpretação tem os seus limites, pois o problema do confiteri deriva da consciência dos próprios pecados. A tendência à vida beata, não in re, mas in spe, nasce somente da remissio peccatorum, ou seja, da reconciliação com Deus. Nós, porém, devemos deixar de lado estes fenômenos, pois são por demais complexos e exigem condições de compreensão que não podem ser alcançadas neste contexto. Todavia, com a nossa reflexão, adquiriremos o elemento fundamental, na ordem da compreensão, para o acesso aos fenômenos do pecado, da graça, etc. ${ }^{39}$

mudando "o centro de gravidade da vida factual e do mundo da vida no mundo do si", cf. HEIDEGGER. Grundprobleme der Phänomenologie (WS 1919/20), GA Bd. 58, p. 61-62 e 205.

37 HEIDEGGER. Augustinus und der Neuplatonismus, p. $238-239$ (trad. it., p. 305).

38 HEIDEGGER. Augustinus und der Neuplatonismus, p. 242 (trad. it., 308).

39 HEIDEGGER. Augustinus und der Neuplatonismus, p. 283 (trad. it., p. 360-361). Trata-se de um trecho das notas tomadas durante o curso por Oscar Becker. Uma situação análoga aparece no curso de 1920/21, a propósito da experiência protocristã do tempo, assim como emerge no conceito paulino de kairós em relação à espera da segunda vinda de Cristo (I Tes. 5, 2-3): "o cristão tem a consciência de que esta facticidade não pode ser conquistada com as próprias forças, mas provém de Deus - fenômeno da ação da graça". Mas, por outro lado, para seguir até o fundo a realização da vida em Paulo, deve-se "deixar completamente de lado o conteúdo do anúncio", ou seja, "Jesus enquanto Messias" (HEIDEGGER, M. 
Heidegger afirma com clareza este modo de interpretar também em outros momentos durante os anos vinte: a partir do programa de uma filosofia que, em princípio, enquanto autointerpretação do si-mesmo como pura problematicidade ou inquietude, deve ser fundamentalmente "a-téia" (em sentido fenomenológico, entende-se, não em sentido ideológico), de que Heidegger fala no curso de 1922 sobre as Interpretações fenomenológicas de Aristóteles; até chegar à célebre conferência de 1927 sobre Fenomenologia e teologia, em que a delimitação da hermenêutica ontológico-existencial em relação aos conceitos teológicos da tradição cristã se radicaliza, entendendo a filosofia não somente como o que põe à parte aqueles conceitos, mas também como o que "indica formalmente o conteúdo ôntico, ou seja, pré-cristão", constituindo, enfim, a sua "possível correção ontológica". ${ }^{40}$ Mas é o que já tinha sido claramente sugerido no curso de 1921, quando, evidenciando, a meu ver, o verdadeiro motivo pelo qual é preciso abandonar os fenômenos difíceis da remissão dos pecados e da reconciliação, Heidegger acrescenta (cito sempre das notas de Becker):

Em todo caso, em Agostinho, a consciência do pecado, e o modo em que Deus é presente nesta, encontram-se entrelaçados de forma peculiar com o neo-platonismo. (Por isso a sua concepção do pecado não [...] pode constituir um guia para a explicação fenomenológica do fenômeno "genuíno"). ${ }^{41}$

Aos olhos de Heidegger, portanto, o neoplatonismo de Agostinho não consistiria em uma assunção mais ou menos legítima de categorias gregas para poder traduzir de maneira teórica a irrupção histórica do acontecimento cristão, mas constituiria, ao contrário, o sinal do permanecer deste acontecimento, além de sua irrupção. A própria concepção do si-mesmo como relação com outro, em relação a si, seria neoplatônica. Ou seja, a ação da graça, o que nas Confissões é considerado como a novidade do encontro histórico do eu com Deus através de Cristo, diante de uma concepção "espiritual", mas abstrata do Logos divino, como propunham os "filósofos platônicos". ${ }^{2}$ Por conseguinte, de forma igualmente paradoxal, é como se Heidegger precisasse libertar Agostinho do neoplatonismo, para interpretá-lo em sentido aristotélico,

Einleitung in die Phänomenologie der Religion. In: Phänomenologie des Religiösen Lebens, GA Bd. 60, p. 121 e p. 116 [trad. it., p. 164 e 158-159]).

40 Cf. HEIDEGGER. Phänomenologische Interpretationen zu Aristoteles..., GA Bd. 61, p. 197 (trad. it., p. 224); Id., Phänomenologie und Theologie. In: Wegmarken, GA Bd. 9, p. 66 (trad. it. de F. Volpi, Fenomenologia e teologia, em Segnavia, p. 22).

41 HEIDEGGER. Augustinus und der Neuplatonismus, GA Bd. 60, p. 283-284 (trad. it., p. 361).

42 Sobre a descoberta e sobre a relação de Agostinho com os "filósofos platônicos", ver a passagem explícita de Conf. VII, 9.13 et seq. É significativo, a meu ver, que Heidegger não tome em consideração este documento como relevante em vista do tema "Agostinho e o neoplatonismo". 
visto que somente em Aristóteles estaria salva a descoberta protocristã da "vida"; e a facticidade, quando separada da relação que, segundo Agostinho, a constitui - e em que, também segundo Heidegger, ela foi originalmente descoberta pela primeira vez -, deve ser purificada e absolutizada em relação a toda identidade pessoal - do eu e de Deus ao mesmo tempo. E mesmo neste caso encontramo-nos diante de uma resposta heideggeriana à tendência contextual da "filosofia cristã", e em particular da filosofia neoescolástica alemã (e de Freiburg, em particular), que procurava traduzir e sistematizar o pensamento tomista nas categorias da metafísica aristotélica. Aqui, ao contrário, se trataria de romper o fio e de reatá-lo de outro modo, ou seja, ligando Agostinho (liberado do platonismo) diretamente à concepção aristotélica da vida. ${ }^{43}$

Com a leitura da temptatio, assim como com a consideração da memória, fica claro que a novidade de Agostinho, segundo Heidegger, não é algo irredutível. Ou melhor, mesmo se o seu conteúdo é irredutível - a experiência do "tu", que se revela como tal pelo eu -, este deve ser definitivamente dirigido de forma centrípeta, digamos, endógena, em que a vida - pura kinesis, motilidade - é em relação a si mesma, como autorreferencialidade radical. É em Ser e tempo, numa passagem crucial, onde se trata de justificar a interpretação do ser-aí como "cuidado" (Sorge), que Heidegger enuncia a sua trajetória hermenêutica de Agostinho a Aristóteles:

O ponto de vista adotado na atual analítica existencial do ser-aí a propósito do cuidado revelou-se ao autor durante a tentativa de uma interpretação da antropologia de Agostinho (ou seja, greco-cristã) em referência aos fundamentos essenciais atingidos na ontologia aristotélica. ${ }^{44}$

O que nasce, em senso plenamente histórico do que começou como graça (ou seja, como um ser-doado do si que não pode ser reconduzido completamente ao si) é identificado como physis, mas certamente não como um simples retorno à situação pré-cristã do vivente, mas na pretensão de oferecer uma interpretação mais radical, ou mais "completa", da descoberta cristã ou seja, histórica - da vida. Heidegger não desconhece que na experiência dos (primeiros) cristãos - como Paulo e Agostinho demonstram - acontece a descoberta que "a realização supera a força do homem", e que não é sequer "pensável na base das próprias forças". Somente que isto não pode se resolver, em direção contrária, através de um simples recurso a Deus, considerado de forma imprópria - ou "ímpia" - como aquilo em que se quer "encontrar 
"um amparo"” ("ein Halt" haben), porque uma tal solução ao máximo levaria a criar uma "visão cristã do mundo" (ou seja, "um autêntico contrassenso"), e, portanto, representaria um bloqueio, mais do que uma atuação da vida factual..$^{45}$ Porém, segundo Heidegger, para salvar o ser "recebido" do si-mesmo, e portanto a sua facticidade, precisa mostrar que a atuação da existência é a sua impossibilidade de se realizar. Aqui está o ponto dramático do processo de interpretação de Heidegger em relação à descoberta de Agostinho: a doação de si não somente deve permanecer ontologicamente diferente do que é doado (do dado!), para evitar sua redução aos significados ôntico-mundanos, mas deve ser liberada, por assim dizer, também do doador, visto que o destino inevitável do si-mesmo em relação a quem o dá (Agostinho é explícito: em relação a quem o "cria", ou seja, ao pai de uma geração) é o de se tornar agora um apoio extrínseco em relação à vida. Nesta suspensão ontológica, a relação - como fenômeno peculiar da vida do si - no final deverá abandonar os relacionantes: não somente o "tu", mas também o "eu" voltam a ser impossíveis, e não a despeito da experiência de Agostinho, mas por causa desta - eis a aporia sem solução por parte de Heidegger.

5 Para concluir, gostaria de mencionar brevemente a passagem que se realiza em Heidegger da inquietude da vida agostiniana, interpretada como pura facticidade, à determinação desta facticidade, nos termos aristotélicos de uma cinética da existência.

Entre os diferentes exemplos da leitura apaixonada e intensa que Heidegger dedica a Aristóteles nos anos vinte, escolho somente dois, particularmente indicativos do percurso que procurei indicar até agora: o assim chamado Natorp-Bericht (o relatório Natorp), escrito por Heidegger em 1922 (portanto, um ano somente após o curso sobre Agostinho e contemporaneamente ao curso de 1921/1922 com o mesmo título, ou seja, Interpretações fenomenológicas de Aristóteles) como um programa de trabalho em vista de uma ampla pesquisa sobre Aristóteles, não publicada, mas que contribuiu à sua chamada à Universidade de Marburg (1923), e um curso universitário sobre os Conceitos fundamentais da filosofia aristotélica proferido em Marburg em 1924.

No Natorp-Bericht se trata da possibilidade de uma autointerpretação da vida, não como uma tematização teórica da existência, mas como o modo mais apropriado com o qual o ser-aí existe. Quando se descobre que esta hermenêutica da facticidade já está sempre orientada e tacitamente guiada por 
precisas "tendências interpretativas" (mais exatamente, como visto, pela "interpretação greco-cristã da vida"), precisará individuar na Destruktion de sua história não somente o meio mais adequado para preparar (auflockern) um terreno endurecido e novamente se apropriar das motivações lógico-ontológicas fundamentais do viver, mas uma modalidade estrutural - uma motilidade originária - com a qual a vida vive si mesma. ${ }^{46}$ Aristóteles constitui um dos campos privilegiados desta preparação do terreno, não somente por razões histórico-filosóficas (por exemplo, pelo fato de que são suas as categorias que permeiam ainda a nossa linguagem), mas por um motivo mais essencial, ou seja, pelo fato que no pensamento aristotélico ocorre a mais decisiva - mesmo se ainda não compreendida em toda a sua dimensão - autointerpretação da vida em termos de "movimento".

Daqui uma atenção particular - ao lado da Metafísica e da Ética a Nicômaco - dada à Física, que, a meu ver, constitui uma espécie de horizonte problemático último no interior do qual se colocam todas as interpretações heideggerianas de Aristóteles, algo como uma posição fundamental (a que identifica a interpretação como movimento do ser-aí) que abre a perspectiva de todos os outros problemas. Se é verdade - como se pode deduzir também somente da lista dos cursos e dos seminários de Heidegger nos anos vinte entre Freiburg e Marburg ${ }^{47}$ - que ele, por exemplo, dedicou intensamente a sua atenção a obras como a Retórica e o De Anima, permanece o fato que é na pesquisa sobre a physis que deve ser procurada "a aquisição das categorias primárias que Aristóteles aplica na sua ontologia". ${ }^{48}$

Lemos no Natorp-Bericht que para compreendermos as mudanças decisivas na história da antropologia ocidental, no nível ontológico, "é preciso dispor de uma interpretação concreta da filosofia aristotélica, orientada na base do problema da facticidade, ou seja, na base de uma antropologia fenomenológica radical". Ora, isto é possível, ou mesmo necessário, pelo fato que "na sua Física Aristóteles ganha, em linha de princípio, uma nova posição fundamental, da qual derivam a sua ontologia e a sua lógica", e que se concentra no zentrales Phänomen que é "o ente no como do seu ser-movido". ${ }^{49} \mathrm{Em}$ outros termos,

46 Cf. Natorp-Bericht, p. 249 (trad. it., p. 510-511).

47 Cf. a lista dos cursos e seminários heideggerianos em VOLPI, F. (Org.). Guida a Heidegger, p. 325-345.

48 HEIDEGGER, M. Grundbegriffe der aristotelischen Philosophie (SS 1924), GA Bd. 18, hrsg. v. M. Michalski. Frankfurt am Main: Klostermann, 2002. p. 284. A este propósito, ver as considerações em HEIDEGGER, M. Phänomenologische Interpretationen augewählter Abhandlungen des Aristoteles zur Ontologie und Logik (SS 1922), GA Bd. 62, hrsg. v. NEUMANN, G. Frankfurt am Main: Klostermann, 2005 (em que a referência à Física limita-se aos cap. 1-4 do livro I, e, em particular, à crítica aristotélica em relação aos eleatas).

49 Natorp-Bericht, p. 251 (trad. it., p. 513). É preciso lembrar que, se aqui o discurso trata da antropologia, esta deve ser entendida sempre a partir de seu caráter "fenomenológico radical": com efeito, Heidegger, já nestes anos, não utilizará mais o termo "antropologia" (acabando claramente por estigmatizá-lo), mas 
se é verdade que no interior desta posição fundamental deve ser encontrado o sentido com o qual se experimenta e se interpreta o ser-homem, ou seja, o "estar em vida" (im Leben Sein) do ser-aí; então vai ser somente neste contexto ontológico que pode se tornar acessível, concebível e definível (zugänglich, faßbar und bestimmbar) o significado dominante do ser. E, portanto, mais uma vez:

As pesquisas cujo objeto é experienciado e compreendido em seu caráter de sermovido - um caráter em que sempre é dado ao mesmo tempo algo como o movimento - devem tornar possível o acesso à fonte genuína dos motivos da ontologia aristotélica. Uma tal pesquisa é realizada na Física de Aristóteles. ${ }^{50}$

Somente no movimento da vida factual, entendida como "cuidar", ou seja, no ter a ver com o que se encontra no próprio mundo-ambiente, decaindo continuamente nas ocupações mundanas e ao mesmo tempo no contramovimento da existência, ou seja, na inquietude ou preocupação para o próprio si em que é implicado o próprio autêntico ser - somente nesta motilidade podese compreender o sentido do ser. ${ }^{51}$

Seria interessante seguir (mas aqui podemos somente mencioná-lo) o modo em que a posição fundamental adquirida na Física está na base das interpretações heideggerianas das diferentes estruturas ontológicas e das plurívocas experiências do pensamento aristotélico, e as atravesse. É suficiente mencionar, permanecendo sempre no contexto exemplificativo do programa de 1922, como Heidegger interpreta as virtudes dianoéticas de que Aristóteles fala no livro VI da Ética a Nicômaco, e em particular a relação entre a phronesis, a sophia e o nous, seguindo como fio condutor "o ser da vida [...] considerado como uma motilidade que tem em si mesma o seu decurso [als an ihm selbst ablaufende Bewegtheit]", e que se realiza cada vez

falará de "hermenêutica da facticidade" (ver o curso homônimo de 1923) e de uma "analítica da existência" (distinta de toda antropologia: cf. Sein und Zeit, § 10). Sobre a passagem da ideia de uma "antropologia filosófica" a uma "metafísica do ser-aí", ver HEIDEGGER, M. Kant und das Problem der Metaphysik (1929), GA Bd. 3, hrsg. v. F.-W. von Herrmann, Frankfurt am Main: Klostermann, 1991. §§ 36 et seq. (trad. it. de M. E. Reina, revista por V. Verra, Kant e il problema della metafísica. Roma-Bari: Laterza, 1981).

50 Natorp-Bericht, p. 253-254 (trad. it., p. 515).

51 Cf. Natorp-Bericht, p. 245 (trad. it., p. 505). Talvez valha a pena observar a presença aqui de dois motivos agostinianos, a queda dispersiva nas ocupações mundanas e a inquietude como caráter constitutivo da vida. Somente que em ambos os casos, a escolha interpretativa de Heidegger é claramente reconhecível: a dispersão não é a perda de si, mas é a modalidade estrutural da vida, de modo que o retomar-se no contramovimento do cuidado não é nada mais do que a dispersão, mas a sua assunção como impossibilidade radical do ser-aí (em termos heideggerianos, o seu ter a morte estrutural). E a preocupação inquieta de si não é espera da realização, mas realização ela mesma na suspensão ontológica da facticidade absoluta. A este propósito é preciso remeter à densa análise fenomenológica deste movimento de queda e contramovimento da existência que Heidegger - sempre em um contexto aristotélico - propõe no curso de 1921/22, Phänomenologische Interpretationen zu Aristoteles..., GA Bd. 61, p. 117 et seq. (trad. it., p. 147 et seq.). 
segundo o movimento peculiar de cada virtude, entendidas estas virtudes como "disposições que podem atuar uma custódia genuína do ser". ${ }^{52}$ Mas seria também possível referirmo-nos à interpretação que Heidegger oferece dos livros VII-IX da Metafísica, em que Aristóteles chegaria a uma determinação ontológica da dynamis e da energeia, através de uma explicitação do plano ontológico do movimento (kinesis) e do que se originou do movimento como "movido" (poiesis, praxis). E assim será preciso cada vez conduzir o sentido do ser que o logos determina nas categorias (e que sucessivamente se fixou no sentido da "realidade" e da "efectividade") à motilidade peculiar da vida do ser-aí, constituída como um "ter a ver" (Umgang) com o próprio mundoambiente (Umwelt) e como uma "produção" do ente neste mundo. ${ }^{53}$

No curso de Marburg, em 1924, Heidegger comenta literalmente o terceiro livro da Física de Aristóteles, onde se apresenta a definição do movimento como ato (ou entelecheia) do que é em potência enquanto é em potência, ${ }^{54} \mathrm{e}$ a definição segundo a qual o movimento é a entelecheia do móvel enquanto móvel. Na leitura heideggeriana acentua-se em particular a passagem do capítulo 3, quando Aristóteles trata da aporia lógica que surge ao considerar o movimento como o que se exercita, ou melhor, como o que propriamente "é" no móvel. A kinesis é um fenômeno tal que em um único ato - em uma única entelecheia - se encontram o motor (o agente) e o movido (o paciente), de forma que o movimento pode ser pensado como a distância, única, que marca o intervalo entre dois pontos (o um e o dois, ou o caminho que liga Tebas a Atenas): uma mesma distância que pode ser percorrida indiferentemente por um ou pelo outro dos dois termos. ${ }^{55}$ Em sentido lógico, devemos reconhecer que, ainda que os dois movimentos (o da poiesis e o da pathesis) sejam diferentes entre si, devem, porém, ser pensados em um mesmo sujeito. Mas ação e paixão são inerentes ao mesmo sujeito, pois no movimento o motor é sempre motor de um movido, e o movido é sempre movido por um motor.

Esta co-pertinência do motor e do movido atrai de forma significativa a atenção heideggeriana: "Poiesis e pathesis são determinações de um ente unitário, e este existe [ $d a$ ist $]$ no modo do ser-em-movimento". Um tal fenômeno aparece claramente aos olhos de Heidegger como o ponto mais alto de toda a elaboração do sentido do ser, um sentido que nasce em uma "experiência ainda

52 Natorp-Bericht, p. 255, 260 (trad. it., p. 516, 523).

53 Natorp-Bericht, p. 267 e 268 (trad. it., p. 530-531 e 532). Ver F. Volpi, L'esistenza come praxis. Le radici aristoteliche della terminologia di "Essere e tempo", em VATTIMO, G. (Org.). Filosofia '91, Roma-Bari: Laterza, 1992. p. 215-252.

54 Respectivamente Arist., Phys. III 1, 201a 10-11 e 2, 202a 7-8.

55 Cf. Arist., Phys. III 3, 202a 15 et seq., 202b 11 et seq. 
não exprimida no ser-aí [Dasein] do mundo e da vida". ${ }^{56} \mathrm{O}$ movimento, como unidade de atuação do motor e do movido, é um traço essencial para entender o ser da vida como autoatuação e para entender o ser dos entes como presença:

O ente em movimento foi determinado como presencialidade [Gegenwärtigkeit] do ente no seu poder-ser [esta a tradução heideggeriana de energeia ou entelecheia e de dynamis]. Kinesis determina também o "aí" [do ser aí ou existir: o Da do Dasein] do ente em movimento, do movido. Mas o movido (note-se o pros ti) é ser em relação ao motor, no com-ser-aí de um kinoun e de um kinetikon. Mas como deve ser determinado o "aí" deste último ente em movimento que coexiste com este enquanto movido? ${ }^{57}$

Não se vai tratar - como sabemos - de dois tipos diferentes de energeia, ou seja, de "presencialidade" do ente que atua, mas de uma única atuação:

uma única e mesma [presença], a qual - a condição de ser compreendida neste modo - constitui o sentido corretamente entendido do "aí" do ente em movimento, do ente que se move (physei onta, que se move a partir de si) [...]: ser-presente no "aí", mover. O motor e o movido estão no mesmo "ai"'. [...] Ser-movido é ser no com-ser-aí [Mitdasein] do motor. ${ }^{58}$

O movimento da vida pode, portanto, implicar, constitutivamente, ou seja, compreender, o ser do ente, enquanto este pertence ao ser automovente da própria vida. Eis o jogo heideggeriano: o que Aristóteles descreve como o ser do ente da natureza é atribuído à constituição do si, da vida do ser-aí; e o ser-aí, como ser no mundo, torna-se, por sua vez, o horizonte interpretativo último para compreender o ser do ente e o próprio sentido do ser. ${ }^{59}$ Ter em si a origem e o princípio do movimento (a vida, o ser-aí, a existência) coincide com a significação ontológica mais radical, a dinâmica escondida que permanece sob toda a história da ontologia. A descoberta e a aquisição próprias a Agostinho são literalmente colocadas em movimento, não mais, todavia, a partir de seu aparecer histórico, mas, ao contrário, separadas pelo evento de sua proveniência. E assim a relação dramática com a origem - o que para Agostinho significa essencialmente "viver" na descoberta do "tu" - se inverte na impossibilidade da origem como sentido único da vida do ser-aí: o ente que se "move" a partir de si mesmo.

56 HEIDEGGER. Grundbegriffe der aristotelischen Philosophie, GA Bd. 18, p. 328, 392.

57 HEIDEGGER. Grundbegriffe der aristotelischen Philosophie, GA Bd. 18, p. 392-393.

58 HEIDEGGER. Grundbegriffe der aristotelischen Philosophie, GA Bd. 18, p. 393.

59 "A questão do ti to on provém da determinação da poiesis e do ser-aí-presente - poiesis como ser-nomundo em sentido primário, praxis" (HEIDEGGER. Grundbegriffe der aristotelischen Philosophie, GA Bd. 18, p. 329). 